\title{
A new karyotype of Wiedomys pyrrhorhinus (Rodentia: Sigmodontinae) from Chapada Diamantina, northeastern Brazil
}

\author{
Ana L. G. Souza', ${ }^{1}$; Margaret M. de O. Corrêa ${ }^{1}$; Cecília T. de Aguilar² \& Leila M. Pessôa ${ }^{1}$ \\ ${ }^{1}$ Laboratório de Mastozoologia, Departamento de Zoologia, Instituto de Biologia, Universidade Federal do Rio de Janeiro. \\ Avenida Brigadeiro Trompowsky, bloco A, sala A1-121, 21940-590 Rio de Janeiro, RJ, Brazil. \\ ${ }^{2}$ Laboratório de Ictiogenética, Departamento de Genética, Universidade Federal do Rio de Janeiro, Rio de Janeiro, Avenida \\ Brigadeiro Trompowsky, Ilha do Fundão, 21940-590 Rio de Janeiro, RJ, Brazil. \\ ${ }^{3}$ Corresponding author. E-mail: ana.lgs@gmail.com
}

\begin{abstract}
A new karyotype of Wiedomys pyrrhorhinus (Wied, 1821) is described, including G- and C-banding and AgNOR sites from specimens collected in the municipality of Morro do Chapéu, situated in the northern region of the Chapada Diamantina, state of Bahia. Karyological studies of W. pyrrhorhinus have shown a constant diploid number (2n) of 62 with two different numbers of autosomal arms (FNa): 86 and 90, respectively. The new karyotype revealed $2 \mathrm{n}=62$ and $\mathrm{FNa}=104$, being the higher autosomal number found so far for this genus. The $\mathrm{X}$ chromosome is a large acrocentric and the $\mathrm{Y}$ chromosome is a small acrocentric. The analysis of the karyotype morphology suggests that this new karyotype is more closely related to the previous karyotype with $2 \mathrm{n}=62$ and $\mathrm{FNa}=90$, described from Caetité, Bahia State. Further studies, comparing different populations of W. pyrrhorhinus, including molecular approaches, may help to better understand the geographical limits of each population and their phylogenetic relationships in the Caatinga biome.
\end{abstract}

KEY WORDS. Ag-NOR sites; Caatinga; C-banding; G-banding; red- nosed mouse.

The red-nosed mouse, Wiedomys pyrrhorhinus (Wied, 1821), was originally described from Riacho da Ressaca, state of Bahia, Brazil, as belonging to Mus Linnaeus, 1758. HershKovitz (1959) created Wiedomys to contain W. pyrrhorhinus, and the genus was considered monotypic until recently, when a new species, Wiedomys cerradensis Gonçalves et al., 2005, was described from Jaborandi, Bahia, Brazil.

Wiedomys pyrrhorhinus is widely distributed in northeastern Brazil from Ceará to northern Minas Gerais states (Bonvicino et al. 2008), and is recognized as being endemic to the Caatinga biome (Oliveira et al. 2003).

Two karyological studies carried out on $W$. pyrrhorhinus have shown a constant diploid number (2n) of 62 with two different autosomal fundamental numbers (FNa): 86 and 90 . The karyotype with $\mathrm{FNa}=86$ was described in specimens from Bom Conselho and Cachoeirinha, Pernambuco (MaIA \& LANGGUTH 1987). The karyotype with $\mathrm{FNa}=90$ was found in specimens from Caetité in Bahia (Gonçalves et al. 2005).

The recently described species, $W$. cerradensis, has a karyotype of $2 \mathrm{n}=60$ and $\mathrm{FNa}=88$ (GonçALVEs et al. 2005), with the diploid and autosomal fundamental numbers differing from those found so far for $W$. pyrrhorhinus.

Herein, a new karyotype is described for $W$. pyrrhorhinus including G- and C-banding and Ag-NOR site location, based on samples collected in the municipality of Morro do Chapéu, in the northern region of the Chapada Diamantina, Bahia, Brazil.

\section{MATERIAL AND METHODS}

Two specimens, one male and one female, were collected at Fazenda Salinas, Morro do Chapéu, (11 ${ }^{\circ} 18^{\prime} 45.7^{\prime \prime}$, $\left.41^{\circ} 15^{\prime} 04.0^{\prime \prime} \mathrm{W}\right)$, Chapada Diamantina. The vouchers consist of the skulls, skeletons, baculum and skins, which are deposited in the Mammal Collection of the Museu Nacional, Rio de Janeiro (MN71607 - male and MN71608 - female).

Cytogenetic analyses were performed on mitotic metaphase chromosomes, obtained from bone marrow following Ford \& Hamerton (1956), and the chromosomes were stained with Giemsa. The classification of chromosomes followed Levan et al. (1964) with modifications, based on Guerra (1988). The autosomal fundamental number (FNa) was calculated as the sum of the autosomal chromosome arms, determined by the ratio between the lengths of the long arms (l) and short arms (s). When the arm ratio $(r=1 / s)$ was less than three, the chromosomes were considered biarmed and when the ratio was equal to or greater than three, the chromosomes were considered uniarmed. Trypsin-Giemsa banded chromosomes (G-bands) were obtained, according to SeAbright (1972). The constitutive heterochromatin distribution pattern (C-bands) was revealed, using the barium hydroxide method (Sumner 1972). The silver nitrate staining technique (Ag-NORs) followed the procedures of Howell \& BLACK (1980). 


\section{RESULTS}

Cytogenetic analyses of $W$. pyrrhorhinus from Morro do Chapéu in Bahia revealed a diploid number of 62 chromosomes and an autosomal fundamental number of 104. This karyotype consists of 22 pairs of biarmed autosomes (15 pairs of metacentrics, seven pairs of submetacentrics) and eight pairs of acrocentric autosomes (Fig. 1). The X chromosome is essentially a large acrocentric, intermediate in size between pairs 5 and 6 (Fig. 1). However, in the female, one of the two X chromosomes appeared as subtelocentric, due to the presence of distinct small arms. The $\mathrm{Y}$ chromosome is a small acrocentric (Fig. 3). The G-bands allowed for more precise identification of most of the chromosome pairs (Fig. 2).

C-banding showed conspicuous pericentromeric heterochromatic blocks in 21 pairs of autosomes and in the X chromosome (Fig. 3). In pair 16, the short chromosome arms appear almost totally heterochromatic. The Y chromosome is essentially heterochromatic (Fig. 3).

Silver staining in the 37 analyzed metaphases showed that there are up to four pairs of NOR bearing chromosomes. The NOR sites were telomeric and located on the short arms of some small biarmed and acrocentric chromosomes (Fig. 4). The number of NORs and their locations on multiple chromosomes were further corroborated by a quantitative nucleolus analysis that revealed a maximum of eight nucleoli per interphase nucleus.

\section{DISCUSSION}

Wiedomys pyrrhorhinus specimens from two localities in state of Pernambuco, with a karyotype of $2 \mathrm{n}=62$ and $\mathrm{FNa}=$ 86 , have 13 pairs of biarmed autosomes and 17 pairs of acrocentrics. The $\mathrm{X}$ and $\mathrm{Y}$ chromosomes are also acrocentric (MAIA $\&$ LangGuth 1987). The specimens of $W$. pyrrhorhinus from Caetité, Bahia, with $2 \mathrm{n}=62$ and $\mathrm{FNa}=90$, have 15 pairs of biarmed autosomes and 15 pairs of acrocentrics. The X chromosome is also a medium-sized acrocentric, but the $\mathrm{Y}$ chromosome is a small metacentric (GONÇALVEs et al. 2005). The karyotype of W. pyrrhorhinus from Morro do Chapéu, Bahia, described in this study, also has $2 \mathrm{n}=62$ but differs from the other previously described karyotypes for this species in its chromosomal constitution. The autosomal fundamental number of 104 is the highest observed so far within the genus. Morro do Chapéu is distant $300 \mathrm{Km}$ from Caetite (Bahia State) and both are located in the middle of the distribution of the species. On the other hand the two localities in Pernambuco are located in the extreme range of the species and are distant $560 \mathrm{~km}$ from Morro do Chapéu, in Bahia State.

In the karyotype of $W$. pyrrhorhinus from Bom Conselho and Cachoeirinha, Pernambuco, the largest chromosome pair of the diploid complement is acrocentric (MaIA \& LANGGUTH 1987). Differently, in the karyotype from Morro do Chapéu described in the present study, and in the karyotype from Caetité, Bahia (GonçAlves et al. 2005), the largest chromosome pair is submetacentric. The karyotypes from Morro do Chapéu $(2 \mathrm{n}=62, \mathrm{FNa}=104)$ and Caetité $(2 \mathrm{n}=62, \mathrm{FNa}=90)$ have apparently diverged through the evolution of pericentric inversions at 6 chromosomal pairs. Between the karyotypes from Caetité and Pernambuco $(2 \mathrm{n}=62, \mathrm{FNa}=86)$ there are pericentric inversions at two chromosomal pairs. Confirmation of the relationship among all these karyotypes will only be possible when G-bands of Caetité specimens $(2 \mathrm{n}=62, \mathrm{FNa}=90)$ for this species become available.

Despite the observed divergence in chromosomal constitution between the specimens from Morro do Chapéu, Bahia and those from the two populations in Pernambuco (MaIA \& LANGGUTH 1987), the constitutive heterochromatin distribution patterns observed in all three populations are very similar, with pericentromeric heterochromatic blocks in 21 pairs of autosomes and in the $\mathrm{X}$ chromosome together with a totally heterochromatic Y chromosome. The C-banding pattern described in this study differs from the C-banding patterns observed for the two populations from Pernambuco (MaIA \& LANGGUTH 1987) by the absence of conspicuous heterochromatic blocks in the fourth metacentric chromosome pair.

The chromosomal distribution of the Ag-NOR sites in the Morro do Chapéu specimens described in this study is also similar to the pattern already found in the specimens of $W$. pyrrhorhinus from Bom Conselho and Cachoeirinha, Pernambuco (MAIA \& LANGguth 1987). In all these populations the NORs are telomeric and located on the short arms of up to four pairs of submetacentric and acrocentric chromosomes.

This intra-individual variation in the number of the NORbearing chromosomes may occur because the silver nitrate staining technique stains only the NOR sites active during the previous interphase. Thus, the differences in the number of the Ag-NORs per cell may reflect differences in the number of active ribosomal sites in the last interphase (Thiriot-Quiévreux \& Insua 1992, GaLETTI et al. 1995). This polymorphism in the number of active NOR sites per cell seems to be common in rodents and has been reported for other species (YonenaGa-Yassuda et al. 1992, Svartman \& Almeida 1993, Lima et al. 2003, Souza et al. 2007).

No other genetic studies concerning geographic variation have been previously performed on $W$. pyrrhorhinus. Although the three different cytotypes of $W$. pyrrhorhinus here compared present chromosomal rearrangements that can act as a barrier to gene flow, the impact of pericentric inversions on speciation is still ambiguous. Multiple pericentric inversions involving many chromosomes in the complement may have a cumulative effect on fertility, but may also only lead to high levels of polymorphism and might not be claimed to be responsible for speciation (KING 1993). Therefore, the variation observed among the different populations of $W$. pyrrhorhinus may suggest a case of polymorphism, since the species has a 


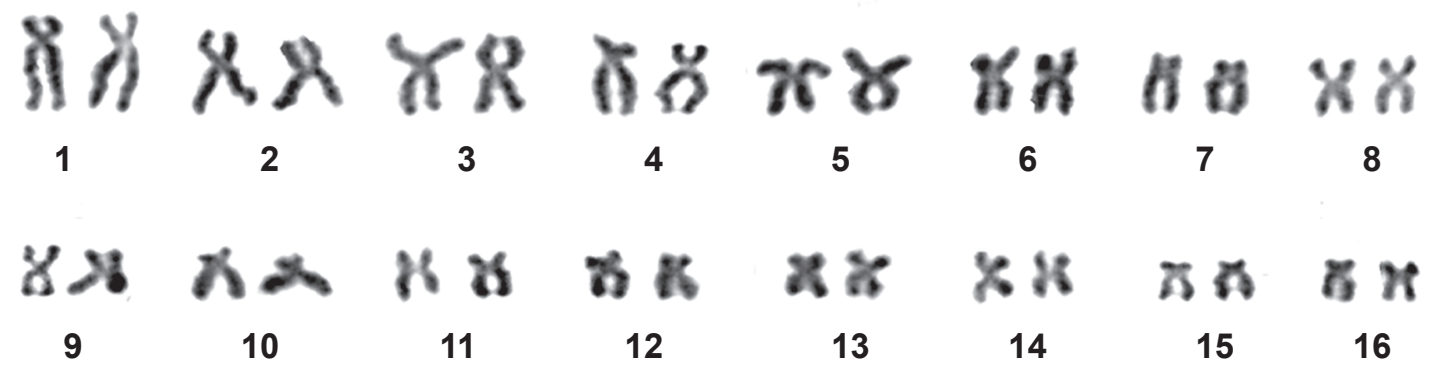

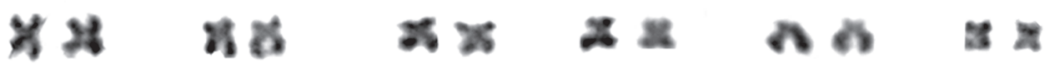

$\begin{array}{llllll}17 & 18 & 19 & 20 & 21 & 22\end{array}$

Ao nn no nh no no son

23

24

25

26

27

28

$29 \quad 30$
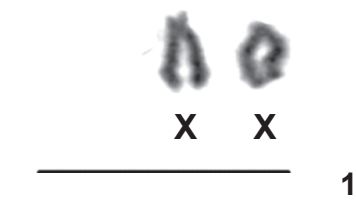

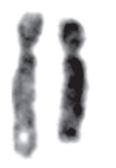

1

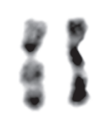

9

81

17

11

23

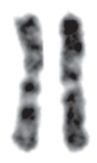

2

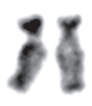

10

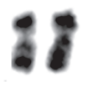

18

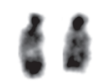

24
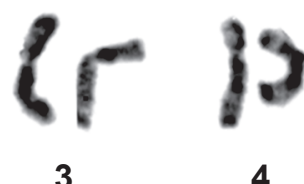

4

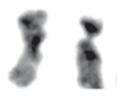

11

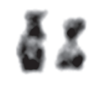

19

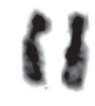

12

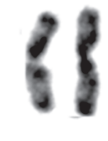

5

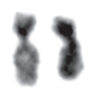

13
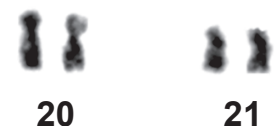

21

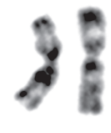

6

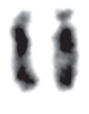

7

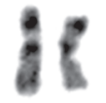

83

14

38

15

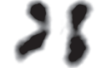

16

\section{1}



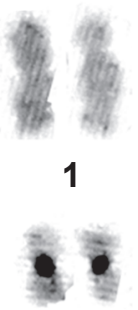

9

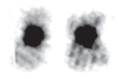

17

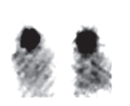

23

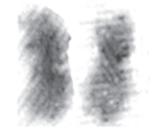

2

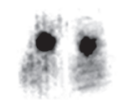

10

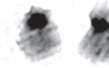

18

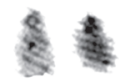

24

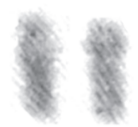

3

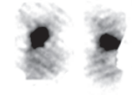

11

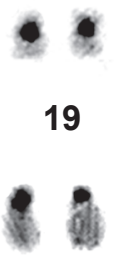

25

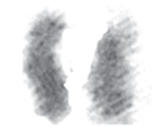

4

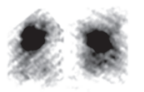

12

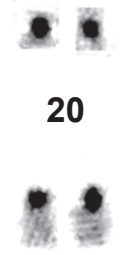

26

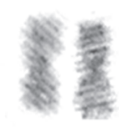

5

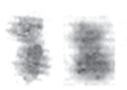

13

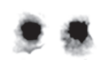

21

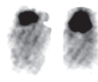

27

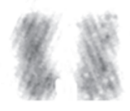

6

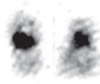

14

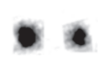

22

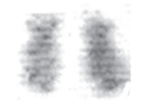

7

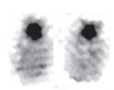

15

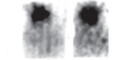

16

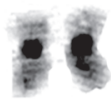

8

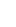


Pessoal de Nível Superior (CAPES) by Programa de Pósgraduação (Zoologia) Museu Nacional,UFRJ, Leila Maria Pessôa is supported by Conselho Nacional de Desenvolvimento Científico e Tecnológico (CNPq). Licenses for collecting were provided by the Instituto Brasileiro do Meio Ambiente e dos Recursos Naturais Renováveis (IBAMA).

\section{LITERATURE CITED}

Bonvicino, C.R.; J.A. Oliveira \& P.S. D'AndRea. 2008. Guia dos roedores do Brasil, com chaves para gêneros baseadas em caracteres externos. Rio de Janeiro, Centro Pan-Americano de febre aftosa - OPAS/OMS, 120p.

Ford, C.E. \& J.L. HAMERTON. 1956. A colchicine hypotonic citrate squash sequence for mammalian chromosomes. Stain Technology 31: 247-251.

Galetti Jr, P.M.; C.A. Mestriner; P.J. Monaco \& E.M. Rasch. 1995. Post-zygotic modifications and intra- and inter-individual nucleolar organizing region variations in fish: report of a case involving Leporinus friderici. Chromosome Research 3: 285-290.

Gonçalves, P.R.; F.C. Almeida \& C.R. Bonvicino. 2005. A new species of Wiedomys (Rodentia: Sigmodontinae) from Brazilian Cerrado. Mammalian Biology 70 (1): 46-60.

GUERRA, M.S. 1988. Introdução à citogenética geral. Rio de Janeiro, Editora Guanabara, 142p.

Hershrovitz, P. 1959. Nomenclature and taxonomy of the Neotropical mammals described by Olfers, 1818. Journal of Mammalogy 40: 337-353.

Howell, W.M. \& D.A. BLACK. 1980. Controlled silver staining of nucleolus organizer regions with a protective colloidal developer: a 1-step method. Experientia 36: 1014-1015.

KING, M. 1993. Species evolution: The role of chromosome change. Cambridge, Cambridge University Press, 336p.

Levan, A.; K. Fredga \& A.A. Sandberg. 1964. Nomenclature for centromeric position on chromosomes. Hereditas 52: 201220.

Lima, F.S.; C.R. Bonvicino \& S. Kasahara. 2003. A new karyotype of Oligoryzomys (Sigmodontinae, Rodentia) from Central Brazil. Hereditas 139: 1-6.

Maia, V. \& A. Langguth. 1987. Chromosomes of the Brazilian cricetid rodent Wiedomys pyrrhorhinos (Wied, 1821). Brazilian Journal of Genetics 10 (2): 229-233.

Oliveira, J.A.; P.R. Gonçalves \& C.R. Bonvicino. 2003. Mamíferos da Caatinga, p. 275-336. In: R.I. Leal; M. Tabarelli \& J.M.C. Silva (Ed.). Ecologia e Conservação da Caatinga. Recife, Editora Universitária.

Seabright, M.A. 1972. A rapid banding technique for human chromosomes. Lancet 2: 971-972.

Souza, A.L.G.; M.M.O. Correa \& L.M. Pessôa. 2007. The first description of the karyotype of Dasyprocta azarae Lichtenstein, 1823 (Rodentia, Dasyproctidae) from Brazil. Mastozoologia Neotropical 14 (2): 227-233.

Sumner, A.T. 1972. A simple technique for demonstrating centromeric heterochromatin. Experimental Cell Research 75: 304-306.

Svartman, M. \& E.J.C. Almeida. 1993. Pericentric inversion and $\mathrm{X}$ chromosome polymorphism in Rhipidomys sp. (Cricetidae, Rodentia) from Brazil. Caryologia 46 (2-3): 219-225.

Thiriot-Quiévreux, C. \& A. Insua. 1992. Nucleolar organizer region variation in chromosomes of three oyster species. Journal of Experimental Marine Biology 157: 33-40.

Yonenaga-Yassuda, Y.; M.F.L. Assis \& S. Kasahara. 1992. Variability of the nucleolus organizer regions and the presence of the rDNA genes in the supernumerary chromosome of Akodon aff. arvicoloides (Cricetidae, Rodentia). Caryologia 45: 163-174.

Submitted: 15.V.2010; Accepted: 15.XI.2010.

Editorial responsibility: Marcio R. Pie 